\title{
Evaluation of the association between dental caries status and middle ear effusion in preschool children in Rasht City
}

\author{
Jalali MM' ${ }^{1}$, Faghih Habibi ${ }^{2}$ A, ${\text { Ramezani } \mathbf{H}^{3}}^{\text {Pam }}$ \\ 1. Professor of Ear, Nose, Throat, Head and Neck Surgery, Otorhinolaryngology Research Center, Department of \\ Otolaryngology and Head and Neck Surgery, School of Medicine, Guilan University of Medical Sciences, Rasht, Iran. \\ ORCID: 0000-0002-7114-5763 \\ 2. Associate of Ear, Nose, Throat, Head and Neck Surgery, Otorhinolaryngology Research Center, Department of \\ Otolaryngology and Head and Neck Surgery, School of Medicine, Guilan University of Medical Sciences, Rasht, Iran. \\ 3. MSc of Nutrition Sciences, Otorhinolaryngology Research Center, Department of Otolaryngology and Head and Neck \\ Surgery, School of Medicine, Guilan University of Medical Sciences, Rasht, Iran (Corresponding Author), Tel: \\ +981333225242, Email: hediehr1392@gmail.com, ORCID: 0000-0003-3227-2644
}

\begin{abstract}
Background and Aim: Considering the effect of middle ear infection and dental caries on the children's quality of life and ability to grow and thrive, high prevalence rates of these diseases in children, we conducted this study to evaluate the association between dental caries status and middle ear infection in preschool children in Rasht City.

Materials and Methods: This study included 310 children between 3-6 years of age. Dental caries of the children were evaluated based on WHO decayed and filled primary teeth index. The children were divided into two groups; with and without caries and referred to Amiralmomenin Hospital in Rasht for clinical examination and audiometry test. Descriptive and analytical statistical tests were used for analysis at the significance level of 0.05 .

Results: 170 girls and 140 boys with mean age of $4.58 \pm 1.02$ years participated in this study. Thirty children $(9.67 \%)$ had middle ear effusion. Mean value of dft index was $2.07 \pm 2.35$. Probability of middle ear infection with effusion in the children with dental caries was $139 \%$ more $(95 \% \mathrm{CI}=1.04-$ $5.50, \mathrm{OR}=2.39)$ than that in the children without dental caries which was statistically significant $(\mathrm{P}$ $=0.04)$. Other variables such as gender, age, education levels of fathers and mothers did not show any significant relationship with middle ear effusion $(\mathrm{P}>0.05)$.

Conclusion: Middle ear effusion was significantly higher in the children with dental caries than in children without dental caries. Further prospective studies are recommended for evaluation of the effects of improved oral hygine on middle ear infection.
\end{abstract}

Keywords: Children, Dental caries, Otitis media, Otitis media with effusion

Received: May 15, 2019

Accepted: August 17, 2019

How to cite the article: Jalali MM, Faghih Habibi A, Ramezani H. Evaluation of the association between dental caries status and middle ear effusion in preschool children in Rasht City. SJKU 2019;24(4):116-124.

Copyright (C) 2019 the Author (s). Published by Kurdistan University of Medical Sciences. This is an open access article distributed under the terms of the Creative Commons Attribution-Non Commercial License 4.0 (CCBY$\mathrm{NC}$ ), where it is permissible to download, share, remix, transform, and buildup the work provided it is properly cited. The work cannot be used commercially without permission from the journal. 


\section{بررسى همراهى وضعيت يوسيدكى دندانى و عفونت توش ميانى با افيوزن در كودكان مهدكودكهاى شهر ستان رشت}

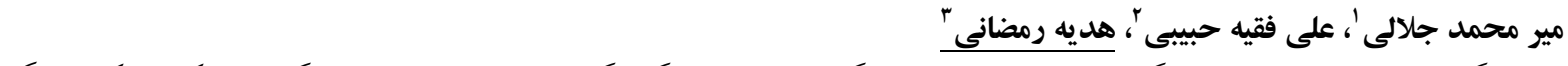

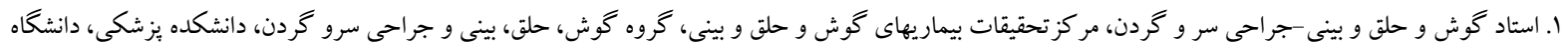

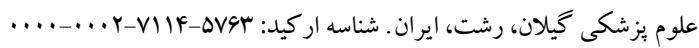

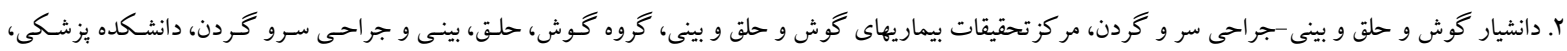
دانشكاه علوم يز شكى كيلان، رشت، اير وان.

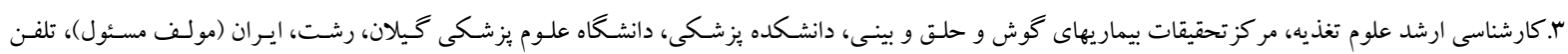

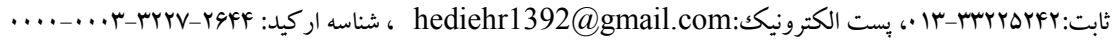

جكيده زمينه و هدف: با توجه به تاثير گذارى عفونت گوش ميانى و بوسيدگى دندانى بر روى كيفيت زندگى كود كان و توانايى رشـــ

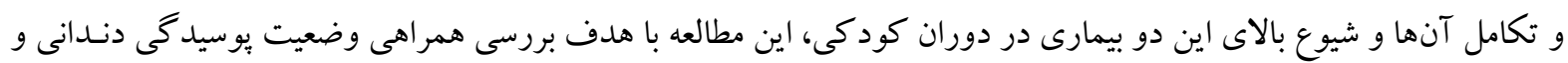

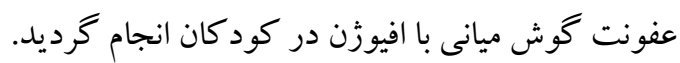

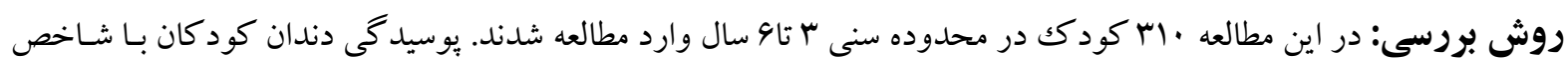

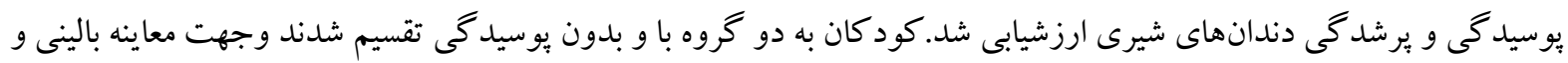

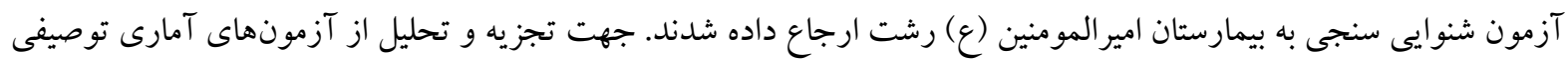

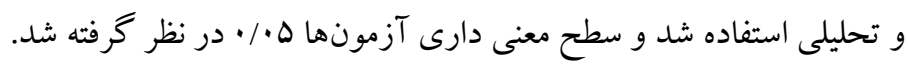

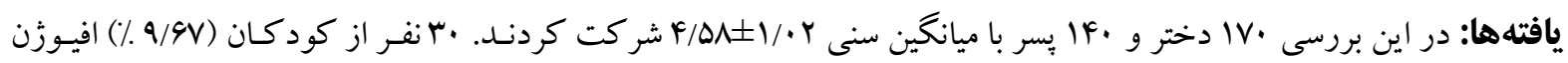

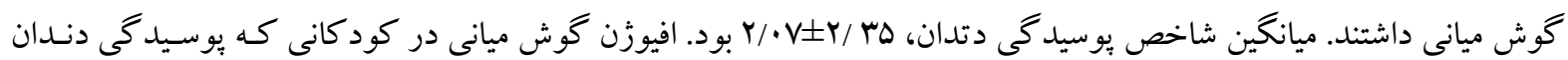

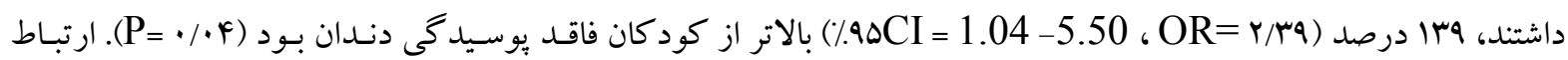

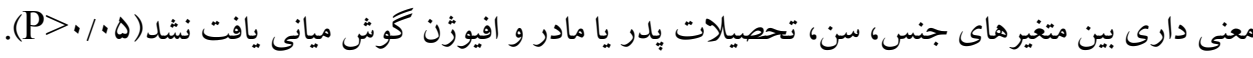

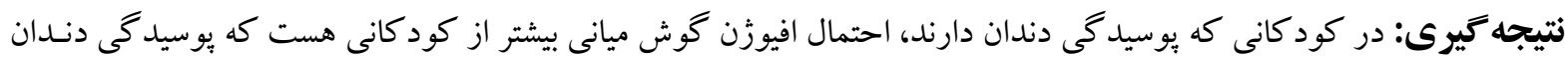

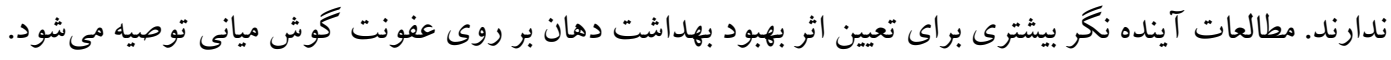

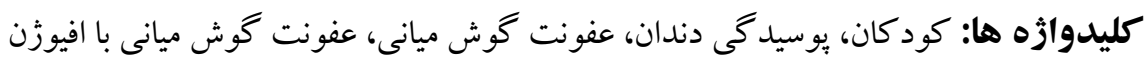


وجود ياتوفيزيولوزى مشابه در بروز اين بيمارىها باشد. در

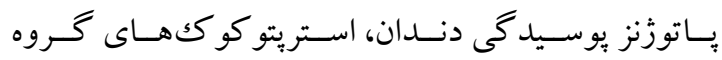
مو تـــانس (بــه خصــوص اســتريتو كو كوس موتسـانس و و

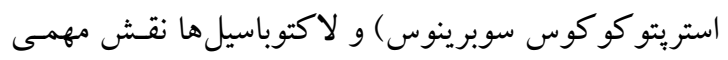

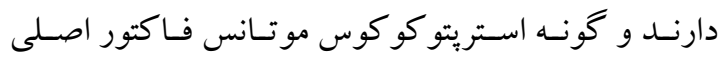

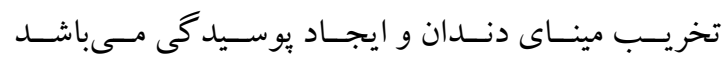

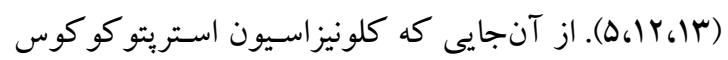
مو تانس مى تواند بر كلونيز اسيون استريتو كو كوس ينومونيسه

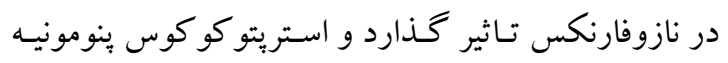

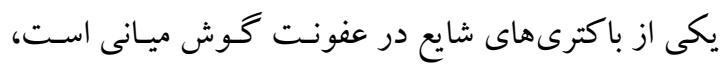

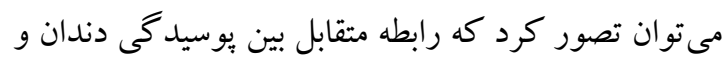

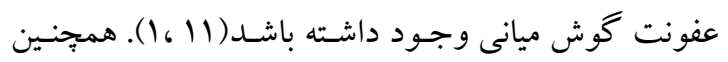

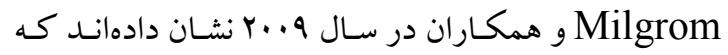

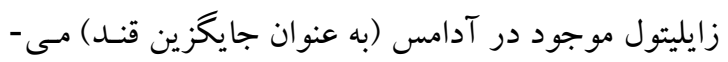

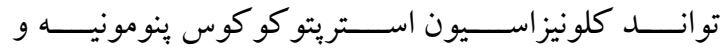
استريتو كو كوس مو تانس را كاهش دهد(f) و بنابر اين مى

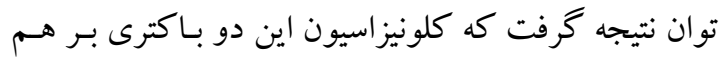

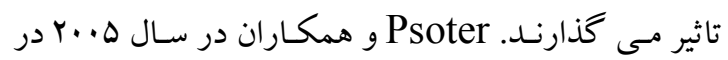
توجيه همراهى اين دو بيمارى، اين احتمال را مطرح كرده-

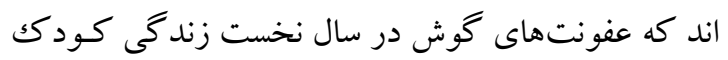
مى تواند سبب هييويلازى مينا در موقع تشكيل دندان شيرى

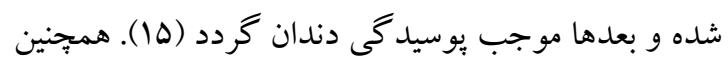

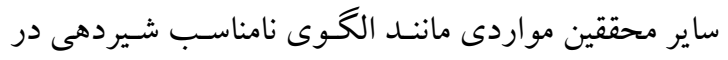

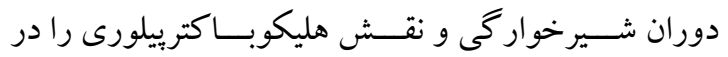
همراهى اين دو بيمارى ذكر كردهانـد(19، VV). بـرخلاف مطالعات فوق، Esra و همكاران در سـال با.بr نتو انستـند اختلافى در تجمع مايع و فشار كوش ميانى در كودكان بـا

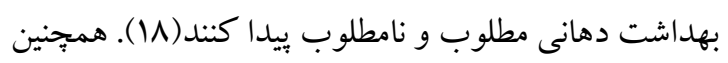
در مطالعه Nelson و همكاران در سال هـ . ب همر اهى بين عفونت گوش ميانى و بوسيدگى دندان مشـاهده نشــ (19).

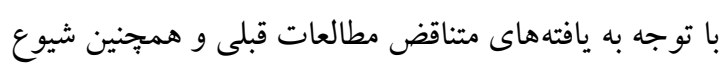

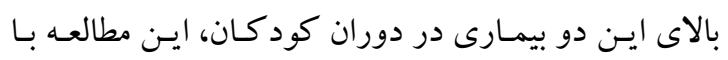

كود كان به ندرت دوران طفوليـت خـود را بـدون ابتلا بـهـ يكك بيمارى عفونى شايع مى گذرانند. عفونت گُش ش ميانى

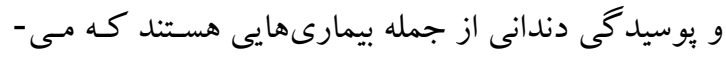

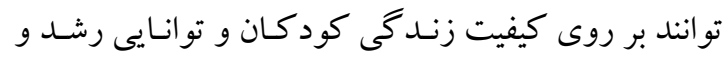

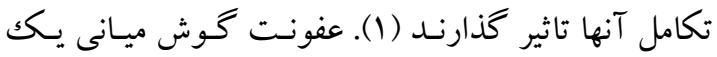

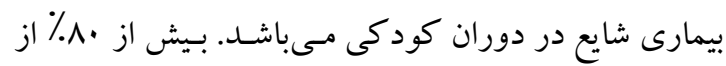

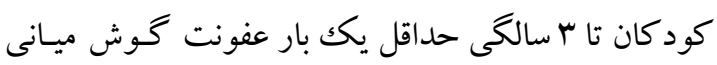

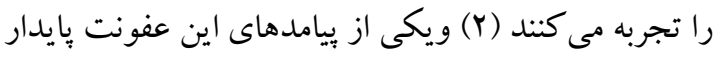

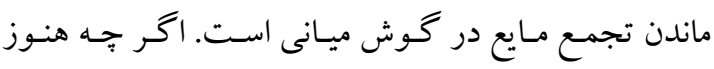
بيمارىزايى تجمع مايع به خوبى مشخص نشده است ولى ولى نس

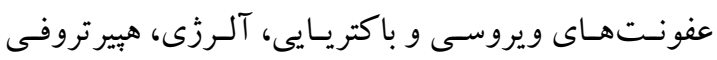

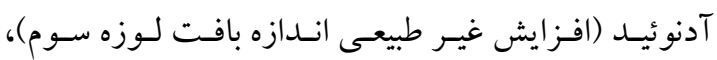

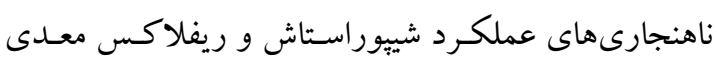

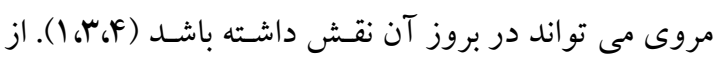

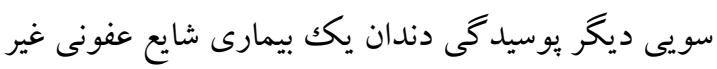

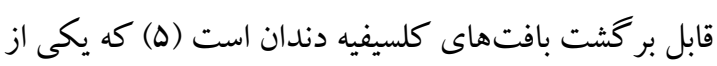
جالشهاى بزر گكى حوزه سلامت دهان به ويزٔه دركود كان

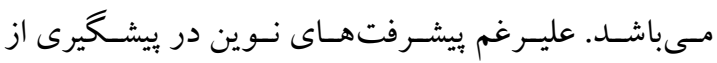

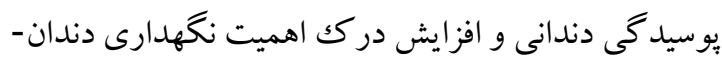
هاى شيرى، هنوز هم بسيارى از دندانها، زودتر از موقع از دست مىروند (9). نواحى مديتر انهاى شرقى، از جمله ايران بالاترين ميانگين شاخص دندانهاى شيرى بوسيده/ نداشته/ يرشـه يـا (dmft) بهداشـت، درمــان و آمــوزش بز شـكى در ســال الهبا،

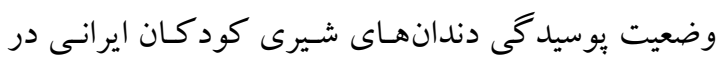

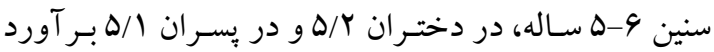

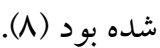
مطالعات در خصوص همر اهى بين عفونت گكوش ميانى و

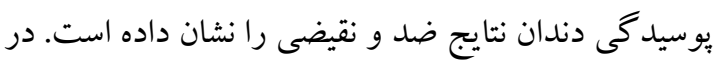

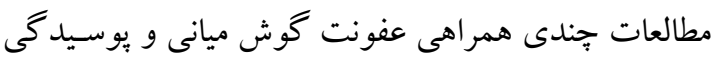

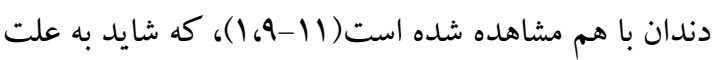


Inventis Harpbasic,

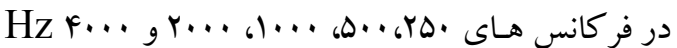

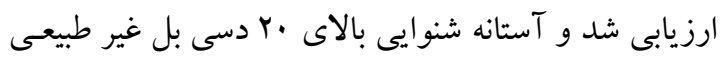

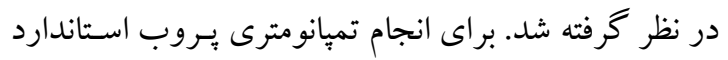

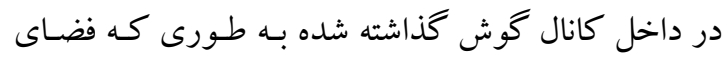

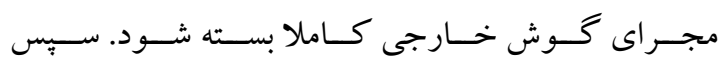

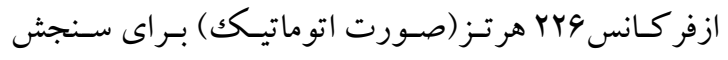

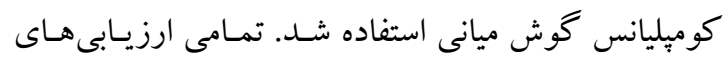
شنوايى در داخل يكك فضاى بى صدا و توسط يكك شنو ايى نوني

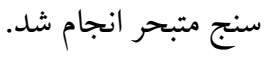

\section{روش آمارى}

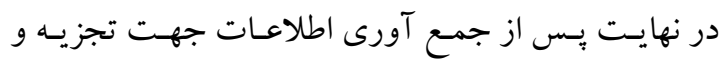

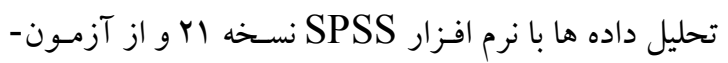

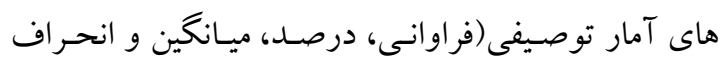

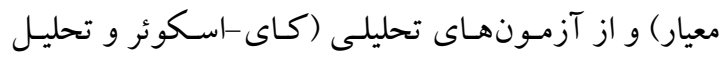

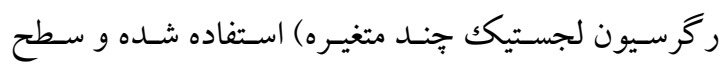
معنى دارى آزمونها هـ • • در نظر كرفته شد.

نتايج

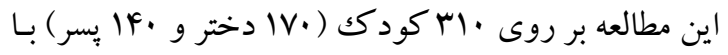
محسـدوده ســى ب تــا و ســال تحست مر اقبـت در جهــار

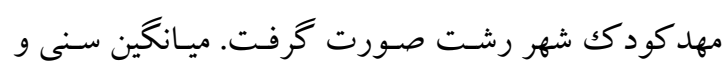
انحراف معيار در يسران و دختران جامعـه مـورد مطالعه بـهـ ترتيسب F+1/

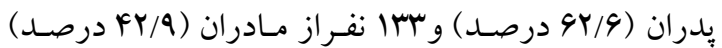

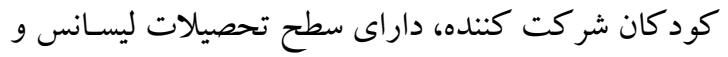
بالاتر از آن بودنــ. هها نفـــ از كل نمونـه مـورد مطالعها

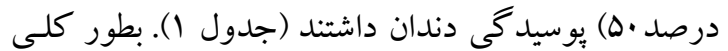
ميانخين و انحراف معيار تعداد دندانهـاى يوسـيده در كل

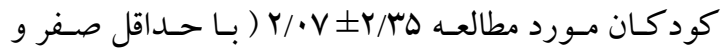
حداكثر هشت دندان يوسيده ) بود و ايـن ميزان در پسـران
هدف بررسى همراهى وضعيت يوسيدگى دندانى و عفونت

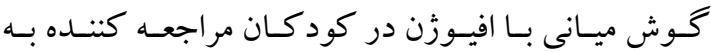
مهد كود ككهاى شهرستان رشت انجام گرديد.

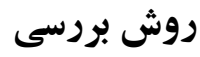

نوع مطالعه

اين مطالعه تحليلى مقطعى (Cross- Sectional) طى

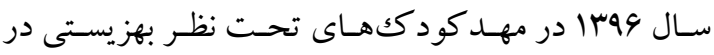
شهرستان رشت انجام شد. ابتدا از بين نه مهدكودكك تحت نظر بهزيستى، بطور تصادفى جهار مهد كود كك انتخـاب شـد و معيار ورود شامل كود كان ب تـا 9 سـاله بـود و معيارهـاى نهاى خروج، كود كان با آنومالى هـاى كرانيوفاسيال (ناهنجارى جمجمه و صورت)، وجود هاييرتروفى آدنوئيد، خرويـف، تاريخجه آلـرزى، وجـود بيمـارىهـاى سيستميكك و عـدم رضايت والـدين يـا عـدم همكـارى كودك در در ارزيابى و

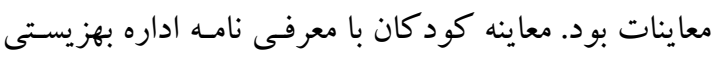

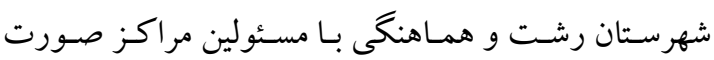

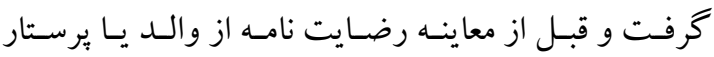
كودك كرفته شد. بيمار يابى جهت ارزيابى يوسيدگى دندان كود كان، با استفاده از نور مناسـب و آينه دندانيز شكى و بـا توجـه بـه معيـار سـازمان

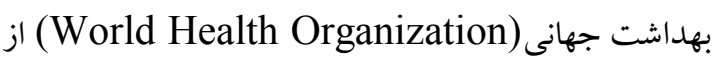

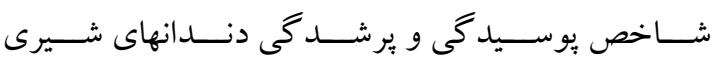
$(Y \cdot)$ decayed and filled primar teeth $(\mathrm{dft})$ يـ استفاده شد. سبس كودكـان بـراى معاينه بـالينى و آزمـون

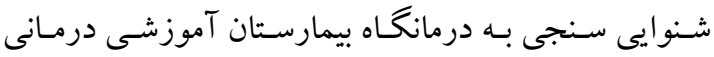

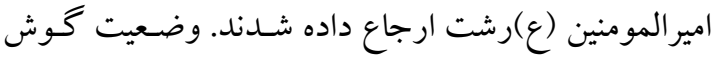

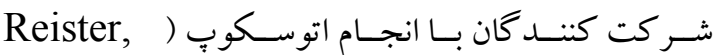
Germany وضعيت برده ى صماخ، سطح مايع - هوا، وجـود رفلكس

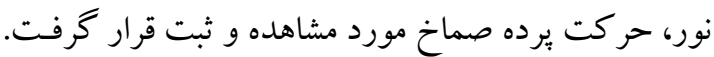

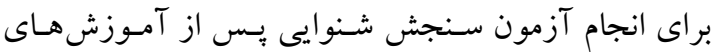
اوليه به كود كان، با استفاده از دستخاه اديومترى ( Italy 


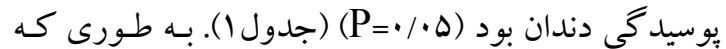
احتمال افيوزن گوش ميانى دركود كان با بوسيدگى دندان بيش از دو برابر (odds ratio] = نسبت شـانس) كود كان فاقد يوسيدگى دندان بود.

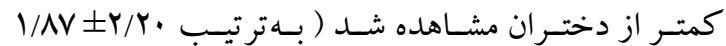
دريسران و

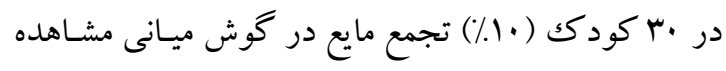

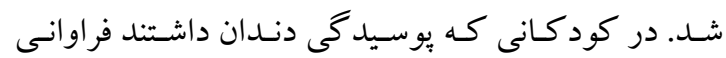

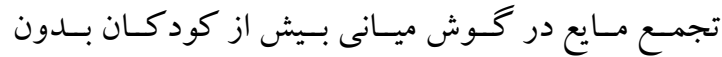

\begin{tabular}{|c|c|c|c|c|}
\hline \multirow[t]{2}{*}{$\mathrm{P}$} & \multicolumn{2}{|c|}{ تجمع مايع در گوش ميانى تعداد(درصد) } & & \multirow[t]{2}{*}{ متغير } \\
\hline & 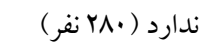 & دارد (· •rنفر) & & \\
\hline \multirow[t]{2}{*}{.$/ \cdot \Delta$} & $\operatorname{lr\Delta }(\Lambda \mathrm{V})$ & $r \cdot(I r)$ & دارد ( دها نفر) & يوسيدگى دندان \\
\hline & $\mid f \Delta(9 \mu / 9)$ & $1 \cdot(G / F)$ & ندارد (هها نفر) & \\
\hline
\end{tabular}

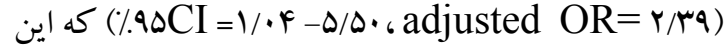

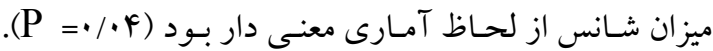
ساير متغيرهاى جنس، سـن، تحصيلات يــر و تحصيلات

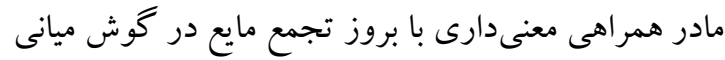

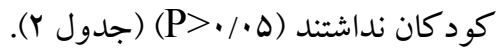

جهت كنترل اثر متغيرهاى مخـدوش كنتـده بـر روى بـروز

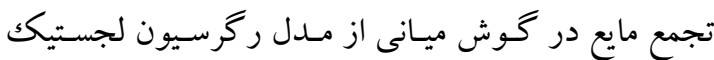

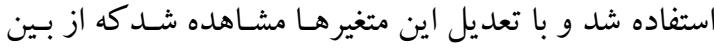
متغيرهـاى مـورد ارزيـابى در هـرزوهش حاضـر تنهـا متغيـر يوسيدكى دندان با افزايش شانس بيشتر در ابتلا بـه عفونـت إنت كوش ميانى با افيوزن همر اه بود.

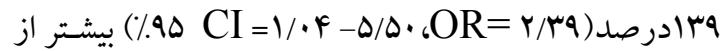

كود كانى است كه يوسيدگى دندان ندارندكه اين ميزان از نتايج بررسى عوامل مرتبط با تجمع مـايع در گـوش ميانى لحاظ آمارى معنى دار مى باشد. ولى ارتبـاط سـاير متغير هـا

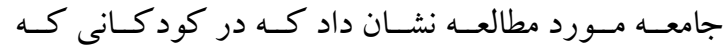

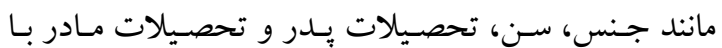

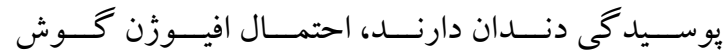


در سال Fehrabkhani تواند به علت جلوتر بودن زمان رويـش دنـدان در دختران

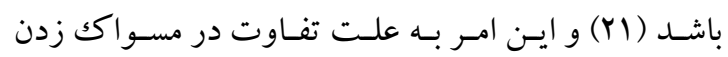

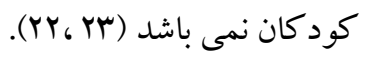

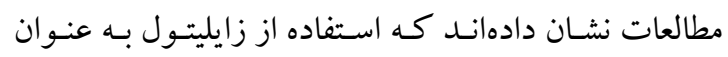
جايكزين قند در آدامس سبب مهار اتصال ينومو كو كك و

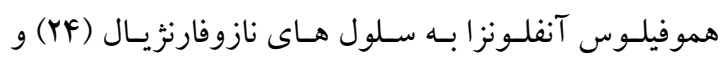

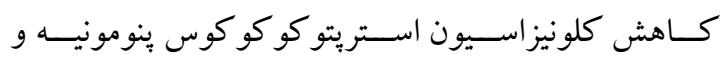

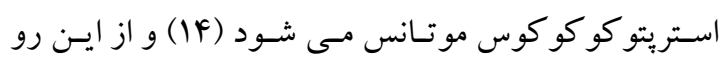
مصرف آدامسهاى مربوطه و بـه طور كلى زايليتول در

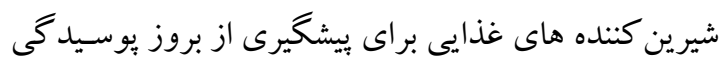

دندانى و عفونت گظش ميانى توصيه شده است (YD).

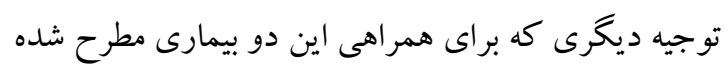

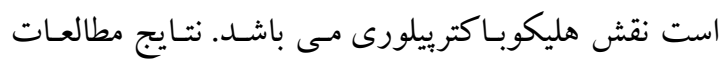

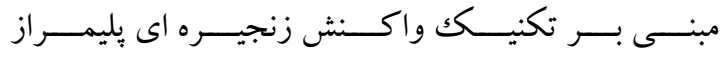
تشـ (ReactionChain Polymerase) هليكوياكتر ييلورى در حفـه دهـان ( بزاق و يـلاكك هـاى

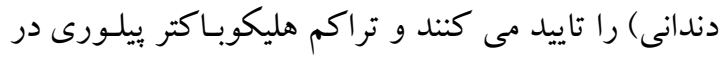

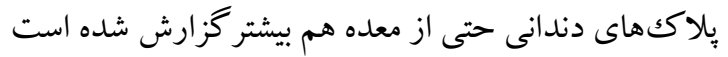

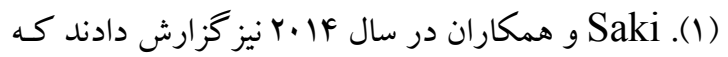
كلونيزاسيون بالاى هليكوباكترييلورى در بافـت آدنوئيسد و

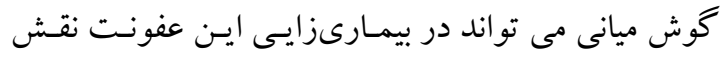
داشته باشد(r). در مطالعه Kolho و همكارانش در سـال

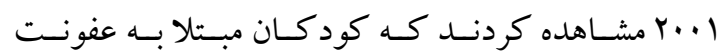

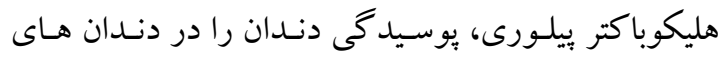

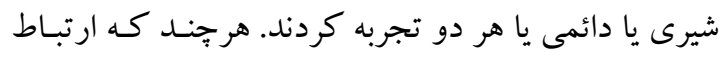

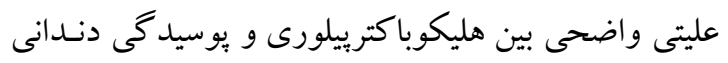

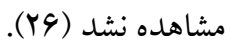

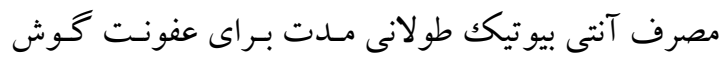

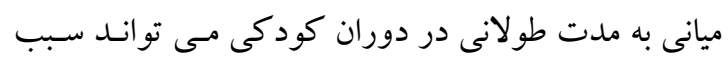

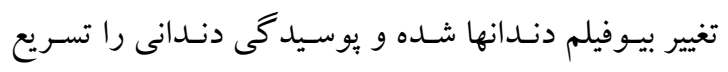
نمايد. همجنين مصرف اين داروها به ويزه آمو كسى سيلين
وجود تجمع مايع در گوش كود كان معنىدار نبود. همسو

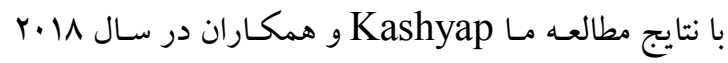

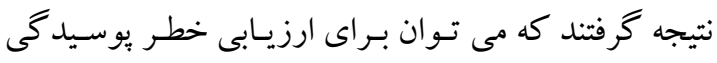

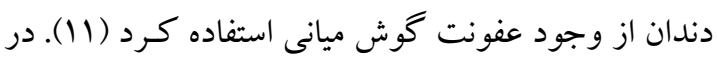

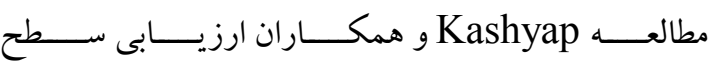

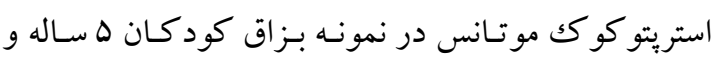

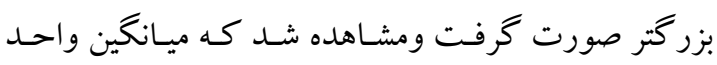

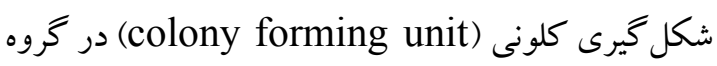

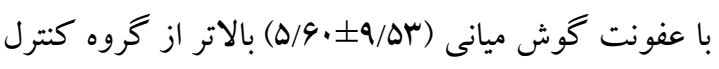
(1/V·ET/MF)

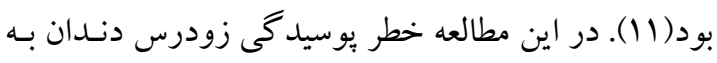

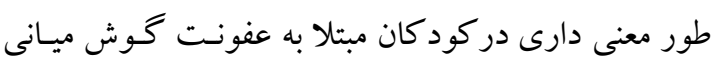

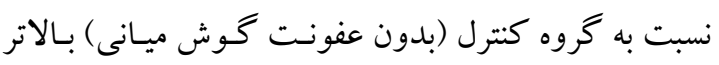

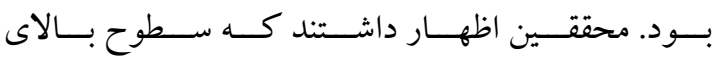

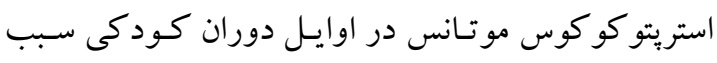

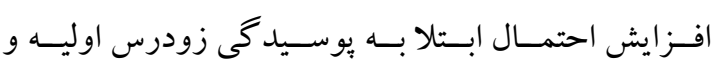

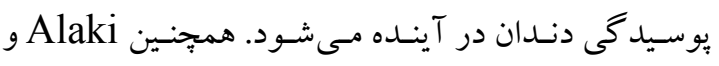

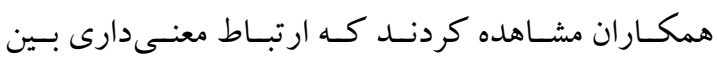

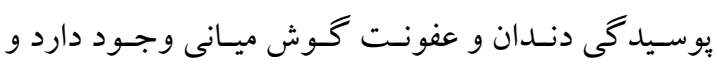

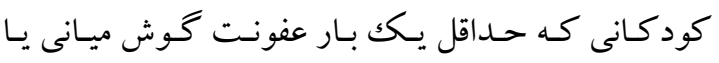

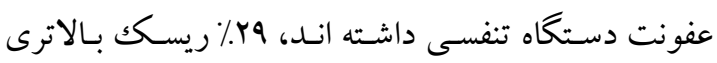
براى يوسيدگى زودرس دندان در مقايسه با كود كان بدون سابقه اين دو عفونت دارند( (1).. برخلاف يافته هاى مطالعه ما كه رابطه معنى دارى بين سن و و

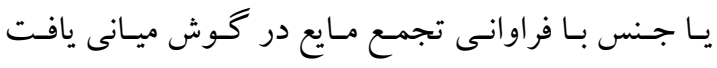

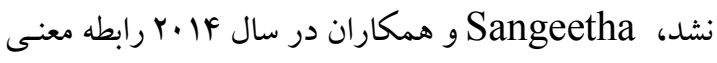

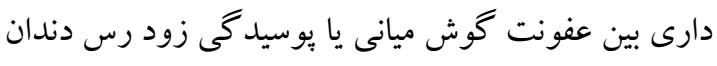

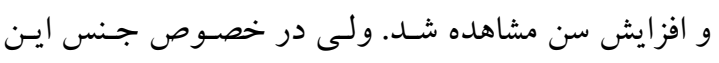

$$
\text { رابطه معنى دار نبود (19). }
$$

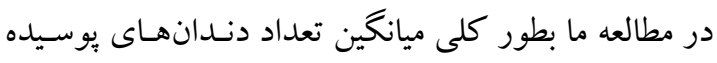

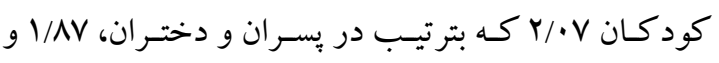

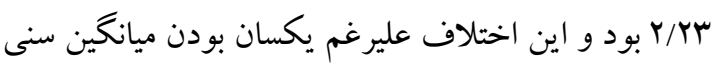

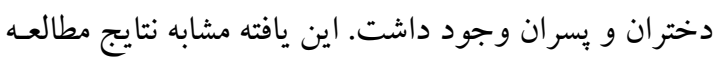




\section{نتيجه كيرى}

با توجه به شانس بيش از دو بر برابرى ابتلا به تجمـع مـايع در

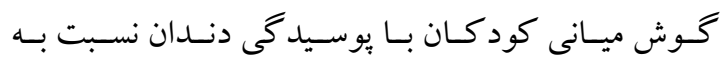

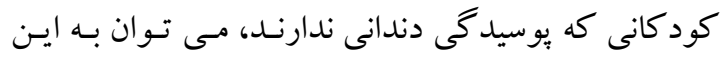

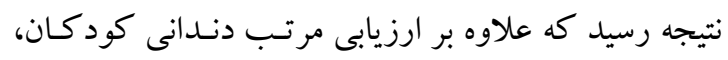

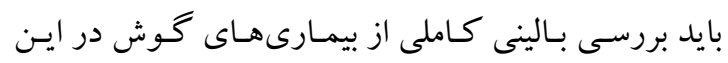

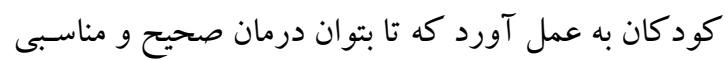

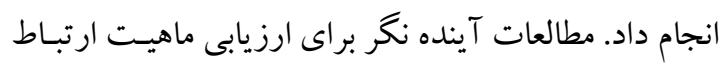

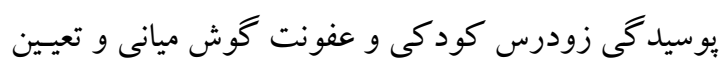
رابطه عليتى بين عوامل مشتر كك اين دو بيمارى توصيه مئشود.

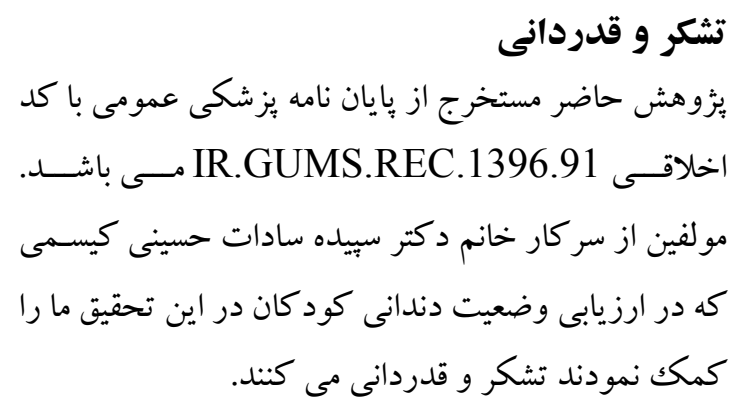

در دوران كودكى مى تواند تكامل ميناى دنـدانى را مختـل نمايد (YV)

$$
\begin{aligned}
& \text { از محدوديت هاى اين مطالعه مى توان به مقطعى بودن نوع }
\end{aligned}
$$

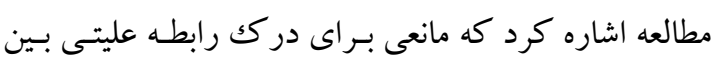

$$
\begin{aligned}
& \text { عفونتهاى دندانى و تجمع مايع در گوش ميانى مى شـود. }
\end{aligned}
$$

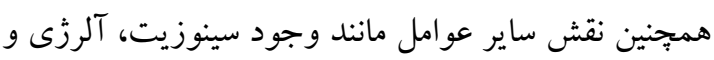

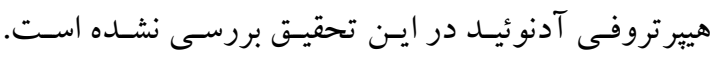

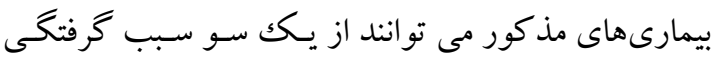

$$
\begin{aligned}
& \text { بينى و تنفس دهانى شده و در نتيجه از طريق خشكى دهل دهان }
\end{aligned}
$$

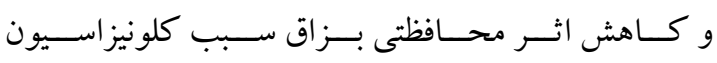

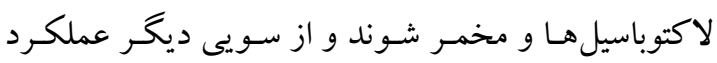

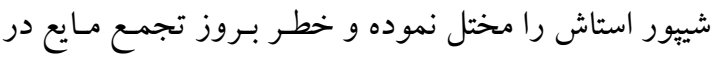

$$
\begin{aligned}
& \text { كوش ميانى را افزايش دهند. محدوديت ديغر اين تحقيق، } \\
& \text { عدم بررسى كامـل وضعيت اجتمـاعى اقتصـادى خـانو اده } \\
& \text { كود كان مىباشد كه مى تواند بر روى سطح تغذيه كود كان }
\end{aligned}
$$

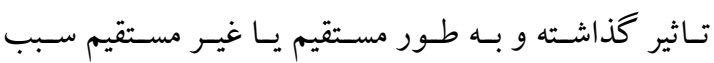

$$
\begin{aligned}
& \text { يو سيدگى دندانى و تجمع مايع در گوش ميانى شـود (YN). } \\
& \text { در اين بررسى تنها سطح تحصيلات والـدين سـنجيده شـده }
\end{aligned}
$$

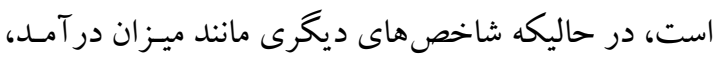

$$
\begin{aligned}
& \text { شـغل و محـل سكونت نيز بـر روى وضـعيت اجتمـاعى و }
\end{aligned}
$$

اقتصادى موثر هستند (1) (1)

\section{Reference}

1. Alaki SM, Burt BA, Garetz SL. Middle ear and respiratory infections in early childhood and their association with early childhood caries. Pediatr Dent 2008;30:105-10.

2.Yadav MK, Vidal JE, Go YY, Kim SH, Chae SW, Song JJ. The LuxS/AI-2 quorumsensing system of Streptococcus pneumoniae is required to cause disease, and to regulate virulence-and metabolism-related genes in a rat model of middle ear infection. Front Cell Infect Microbiol 2018;8:138.

3. Saki N, Zadeh ARS, Jonaky RS, Noori SM, Kayedani GA, Nikakhlagh S. Theprevalence rate of Helicobacter pylori infection in, chronic otitis media with effusion patients. Jundishapur J Microbiol 2014;7:e15694.

4. Jeyakumar A, Bégué RE. Otitis Media with effusion and Helicobacter pylori. OTO Open 2018;2:1-2.

5. Mohammad RK, Azam A, Khoroushi M. Comparison of methods for controlling dental caries in the classical medicine and alternative medical practices and future prospects. J Dent Med 2015;28:122-31. [In Persian] 
6. Ahmadian M ,Arzanlou M, Naghizadeh Baghi A, Imani Rad H, hekmatfar S. Comparative evaluation of antimicrobial activity of three types of materials (reinforced zinc oxide eugenol, MTA and Cem cement) used in primary teeth pulpotomy. SJKU 2019; 23:37-46. [In Persian]

7. Pakpour AH, Hidarnia A, Hajizadeh E, Kumar S, Harrison A-P. The status of dental caries and related factors in a sample of Iranian adolescents. Med Oral Patol Oral Cir Bucal 2011;16:e822-7.

8. Asgari F, Majidi A, Koohpayehzadeh J, Etemad K, Rafei A. Oral hygiene status in a general population of Iran, 2011: a key lifestyle marker in relation to common risk factors of non-communicable diseases. Int J Health Policy Manag 2015;4:343-52.

9. Adler I, Muiño A, Aguas S, Harada L, Diaz M, Lence A, et al. Helicobacter pylori and oral pathology: relationship with the gastric infection. World J Gastroenterol 2014;20:9922.

10. Yılmaz MD, Aktepe O, Çetinkol Y, Altuntaş A. Does Helicobacter pylori have role in development of otitis media witheffusion?. Int J Pediatr Otorhinolaryngol 2005;69:745-9.

11. Kashyap N, Katlam T, Avinash A, Kumar B, Kulshrestha R, Das P. Middle ear infection in children and its association with dental caries. Med Pharm Rep 2019;92:271-76.

12. Karpinski TM, Szkaradkiewicz AK. Microbiology ofdental caries. J Biol Earth Sci 2013;3:M21 -4.

13. Jebali N, Rabbani Khorasgani M, Kianfar M, Emami H.Evaluation of the effects of honey, vinegar and rosewater on adhesion and biofilm formation of Streptococcus mutansand Streptococcus sobrinus. J Isfahan Dent Sch 2016;12:232-47. [In Persian]

14. Milgrom P, Ly KA, Tut OK, Mancl L, Roberts MC, Briand K, et al. Xylitol pediatric topical oral syrup to prevent dental caries: a double-blind randomized clinical trial of efficacy. Arch Pediatr Adolesc Med 2009;163:601-7.

15. Psoter WJ, Reid BC, Katz RV. Malnutrition and dental caries: a review of the literature. Caries Res 2005;39:441-7.

16. Sangeetha P, Prabhawati PI, Inamadar PI, Yendigeri SM, Rai K, Hegde A. Feeding pattern a dual risk? otitis media (OM) and early childhood caries (ECC). Al Ameen J Med Sci 2014; 7:134-40.

17. Patel SK, Pratap CB, Jain AK, Gulati AK, Nath G. Diagnosis of Helicobacter pylori: what should be the gold standard? World J Gastroenterol 2014;20:12847-59.

18. Esra E, Banu OI, Erdinc A. Poor oral hygiene and middle ear infections: any relationship?. Indian J Otolaryngol Head Neck Surg 2013;65:173-6.

19. Nelson S, Nechvatal N, Weber J, Canion S. Dental caries and ear infections in preschoolaged children. Oral Health Prev Dent 2005;3:165-71.

20. Lee J, An S, Song J, Ra J. Relationship between Obesity and Dental Caries in Primary Teeth in Iksan city. J Korean Acad Nurs 2016;43:151-7.

21. Mehrabkhani M, Ajami B, Khademi M, Arastoo S. Evaluating risk factors of dental caries in children under 6-years-old supported by Welfare Organization of Mashhad in 2012. J Mash Dent Sch 2014;38:257-66. [In Persian]

22. Talebi M, Saraf A, Esmaili H. The relationship between diet and oral hygiene and gingival status in private preschool children in the city of Mashhad. Journal of Dentistry. Mashhad University of Medical Sciences 2006;29:223-34. [In Persian]

23. Ingemansson Hultquist A, Lingström P, Bågesund M. Risk factors for early colonization of mutans streptococci - a multiple logistic regression analysis in Swedish 1-year-olds. BMC Oral Health 2014;14:147. 
24. Kontiokari T, Uhari M, Koskela M .Effect of xylitol on growth of nasopharyngeal bacteria in vitro. Antimicrob Agents Chemother 1995;39:1820-23.

25. Uhari M, Tapiainen T, Kontiokari T. Xylitol in preventing acute otitis media. Vaccine 2000;19:S144-S7.

26. Kolho K-L, Hölttä P, Alaluusua S, Lindahl H, Savilahti E, Rautelin H. Dental caries is common in Finnish children infected with Helicobacter pylori. Scand J Infect Dis 2001;33:815-7.

27. Laisi S, Ess A, Sahlberg C, Arvio P, Lukinmaa PL, Alaluusua S. Amoxicillin may cause molar incisor hypomineralization. J Dent Res 2009;88:132-6.

28. Rantala AK, Mehtonen IT, Jaakkola MS, Näyhä S, Hugg TT, Jaakkola JJ. Early Respiratory Infections and Dental Caries in the First 27 Years of Life: A Population-Based Cohort Study. PLoS One 2016;11:e0168141. 